\title{
A filosofia e o filósofo no limiar da era interplanetária
}

\author{
Miguel Reale \\ Catedrático de Filosofia do Direito da Uni- \\ versidade de São Paulo - Presidente do \\ Instituto Brasileiro de Filosofia.
}

\section{I}

Uma realização científica tão prodigiosa, como a dos satélites artificiais, não pode deixar de repercutir profundamente no plano filosófico, sendo impossível prever, desde logo, tôdas as suas consequências de ordem ética ou metafísica.

É óbvio que, sendo próprio da Filosofia elaborar uma cosmovisão, ou seja, uma compreensão geral do universo e da vida, as conquistas das ciências positivas constituem sempre uma de suas componentes essenciais. Se a Filosofia não deve ser considerada mero resultado ou reflexo do saber científico, dêste não pode, todavia, andar divorciado. Dêsse modo, o entreabrir-se da era interplanetária vem alterar alguns dos problemas até agora postos pelo homem, suscitando perguntas que, há bem pouco tempo, mal se vislumbravam na sombra da conjetura e do mistério.

Tôda mudança radical no plano do conhecimento do cosmos redunda, necessàriamente, em alteração na problemática do homem e de sua existência. A perspectiva cosmológica incide diretamente sôbre a antropológica, tão certo como entre o homem e o cosmos intercede um nexo 
essencial de implicação e polaridade, raíz de todos os demais, e razão de ser do processo dialético que governa e torna mais compreensível o complexo da experiência histórica. Nem haverá exagero em se afirmar que o homem vai adquirindo mais plena e rigorosa consciência de si mesmo, da primordial capacidade sintetizadora do espírito, à medida que integra em unidade dinâmica os valores que lhe vêm das formas histórico-culturais por êle objetivadas através dos tempos, e os que promanam do fulcro intencional de sua subjetividade. É do contínuo contemplar-se do homem nas coisas, e do concomitante espelhar-se das coisas no homem, que nasce e se desenvolve a consciência histórica, potenciando a consciência e a objetividade nos ciclos de cultura, mas sem jamais se desprender da fonte espiritual que originàriamente a constitui e a mantém una e concreta.

Não foi, por conseguinte, por mera coincidência que certos momentos cruciais ou decisivos da Filosofia corresponderam a transmutacões operadas na imagem dominante do mundo: foram antes fenômenos correlatos, ou melhor, duas fases ou momentos de um mesmo processo, quando não duas perspectivas de um só evento. A descoberta de novas terras, de "novos mundos", sempre tem influído sôbre o modo de ser e a conduta do homem, mas, indo ao fundo da questão, a descoberta atualizada no plano empírico, já é, em si mesma, um novo modo de ser do homem.

Lembre-se, por exemplo, o que aconteceu quando Marco Polo revelou os mistérios do Oriente, e Colombo deu à ação civilizadora ou transformadora da Europa todo um novo continente. O "homo novus" coincidia com o "novo mundo", traduzindo-se nos valores individualistas de uma época histórica marcada pela ansiedade de tôdas as descobertas. Plasmada uma cosmovisão, em concordância com os ensinamentos de Copérnico, de Galileu e de Newton; dissipada a ilusão geocêntrica do universo, 
pelo abandono da imagem ptolemáica do mundo, o homem nâo se sentiu diminuído, ao ver-se desapossado do centro físico do sistema planetário solar, mas se julgou ainda mais senhor dás coisas, graças à consciência e à compreensão de sua real situação no cosmos.

Aos poucos o planeta tornou-se cada vez menor; cada vez mais unitàriamente abrangido pelo saber e pelas realizações do homem. Concebendo o pensamento como um esbôço necessário de ação; situando o conhecimento das experiências havidas em função de infinitas experiências possiveis, o homem moderno viu a terra como um dominio a ser conquistado, transformado, e, de certa forma, recriado à sua imagem e semelhança, adquirindo novo conteúdo a categoria de possibilidade.

É na linha dêsse desenvolvimento que ainda nos encontramos, embora nos surpreenda a circunstância de, na vertigem de poucos anos, ter podido a ciência penetrar no mundo do infinitamente pequeno, desprendendo as fôrças aterradoras do átomo, e desafiar as distâncias interplanetárias com as suas primeiras mensagens, antecipadoras de viagens surpreendentes "por ares nunca dantes navegados"

Se, no entanto, as realizações de hoje marcam o instante último, mas não derradeiro, de uma civilização caracterizada pelo crescente e contínuo domínio sôbre fôrças da natureza, talvez a simples possibilidade de situarse o ser humano fora da órbita terrestre venha a influir no âmago da Filosofia, alterando-lhe algumas de suas perspeclivas preponderantes.

Até que ponto, pergunto eu, o abandono de uma concepção cósmica geo-cêntrica, - tal como se operou a partir de Copérnico - , teve como consequência o abandono de uma concepção geo-cêntrica do homem e da existência? Ou não terá o homem continuado a pensar "como se" continuasse sendo o centro do cosmos, por ser um caniço frágil, mas um caniço que pensa? 
Por ser a existência do homem uma "existência terrena" (no sentido, é claro, de uma existência circunscrita ao planeta terra, e não no sentido de uma vida ultraterrena "não corpórea") não terá condicionado o nosso modo de pensar e de conceber o problema do homem, da vida e da cultura?

Não me refiro, como se vê, a uma compreensão dos problemas humanos superadora das coordenadas espaçotemporais, ou seja, à valorização da existência à luz de valores transcendentes definitivos ou eternos, mas cuido aqui de uma alteração nas perspectivas de um ser que tende paulatinamente a deixar de ser jungido a um dado planeta para se converter no habitante, não apenas consciente, mas eficiente do cosmos. Uma coisa é contemplar o sistema dos corpos celestes, tentando abrangê-lo "no ato de pensar"; outra coisa é sentir-se capaz de sôbre êle atuar de forma positiva.

Por ora, tudo ainda é perplexidade, nem nos damos conta do valor radical da transmutação operada ante nossos olhos, muito embora alguém possa sustentar que os problemas postos pela Filosofia independem de modificações de ordem empírica, o que me parece contestável, pois a universalidade da Filosofia está antes nos problemas do que nas soluções, e aquêles se renovam e põem outros em função do processo da consciência histórica.

Como se vê, não procede a firmação de que a Nova Física, com a teoria do campo unificado, veio alterar os dados do problema por ter a humanidade descoberto, pela primeira vez, como pretende Malraux, "que a chave do cosmos não é a mesma do homem". Na realidade, ainda que fôsse incontestável a conclusão de que a Filosofia da ciência atual "propõe um universo onde o homem seria sòmente um acidente, não implicando nenhuma noção do homem", estaríamos sem dúvida diante de uma concepção do homem reduzido a mero acidente no cosmos. Inegável 
é, pois a correlação entre "imago hominis ac imago mundi".

Daí poder-se admitir, como hipótese plausivel, que, quanto mais a ciência entreabrir possibilidades de transladação do homem de nosso planeta para outros, mais se tornarão insuficientes as nossas "referibilidades terrenas", e talvez uma nova cosmovisão venha dar novo sentido aos problemas humanos, rasgando outros horizontes à metafísica da existência.

Se os satélites artificiais e a bomba atômica nos permitem, por ora, apenas vislumbrar possiveis mutações de natureza metafísica, tornam, de outro lado, mais agudos e inadiáveis fundamentais problemas de ordem ética.

Em verdade, ao mesmo tempo que nos deslumbramos com os aspectos positivos dos últimos feitos científicos, uma sombra de inquietação desce sôbre os homens. É que ninguém ignora o duplo significado do acontecimento, para as finalidades fecundas da paz, e os objetivos aniquiladores da guerra.

Desde o primeiro satélite artificial, com a sua passageira solitária (e um amante de mitos poderia meditar sôbre o sentido da escolha de uma cachorrinha pacífica para o início do prodigioso ciclo) a nossa mente passa, atribulada, para a imagem dos teleguiados. Surge, assim, diante de nossos olhos tôda a rude competição das grandes potências, cabendo-nos, por ora, assistir, ao espetáculo, na posição incômoda de um espectador que sabe que poderá vir a ser chamado também êle à ribalta, convertido em personagem secundário do drama.

É êste o lado ético do problema. Não mais o satélite artificial visto como elemento metafísico, mas como fator de meditação moral. Na realidade, o que se passa em nossa época demonstra que o progresso científico nem 
sempre vai acompanhado de correspondente progresso ético. $O$ fato de conhecermos melhor o universo, com lôdas as maravilhas da Nova Física, não tem diminuído, mas aumentado as preocupações do homem, paradoxalmente tanto mais aflito quanto mais senhor das leis da natureza.

O que está correndo risco é a própria liberdade instituidora do homem, raiz e fermento de todo o processo histórico, como se as objetivações do espírito sôbre o homem refluíssem para, despregar-lhe as asas de ícaro interceptando a sua escalada audaciosa, para precipitá-lo no abismo cravado entre as suas conquistas teoréticas e a sua infeliz consciência moral.

Nasce dêsse contraste de valores teóricos e práticos a urgência de uma atitude comum entre os homens de pensamento, que deve projetar-se como função pedagógica, a ser desenvolvida não apenas nas universidades, nos colégios, mas alargar-se cada vez mais pelo jornalismo, pelo rádio, o livro e a televisão. Acima de todos os deveres, talvez esteja o de reclamar, para a paz, aquela solidariedade que não tem faltado aos povos nos trágicos momentos de guerra, quando a tudo se renuncia para aniquilar e vencer. Não ignoro que a guerra obedece a fatôres outros de ordem econômica, política, etc. contra os quais muitas vêzes se esboroam os propósitos dos homens de boa vontade. Mas, convenhamos, o momento é de tamanha responsabilidade, ante o futuro da espécie, que bem se poderá parafrasear a antiga advertência: "Quem não tiver medo, que atire a primeira pedra!"

Em suma, estamos no limiar de uma nova era, que avança surpreendentemente, alterando as coordenadas de nosso modo de ser no cosmos. Convicções geo-cêntricas, que ainda subsistiram na época de Newton, cederão talvez lugar a novas perspectivas de um universo concebido segundo o relativismo de Einstein, em uma concepção pluricêntrica. O Direito Internacional, a História, a Política, 
tudo está em causa. Antes de mais nada, está em causa o homem, que mais do que nunca deve ter ouvidos para algo inão menos surpreendente do que as mensagens captadas dos satélites artificiais: os ditames de sua inquieta consciência moral.

Se derem ouvidos a tais ditames, os proprios homens de ciência se aperceberão de que a ciência põe um problema que cabe à Filosofia resolver: o do destino da ciência como instrumento de vida.

Esta verdade cresce de pêso quando pensamos que, mais do que nunca, as ações aniquiladoras estão na dependência direta dos homens de pensamento. Não se deve olvidar que bastaria a ação voluntária, a recusa heróica de algumas centenas de sábios para se tornarem inviáveis as decisões mais temerárias dos Chefes de Estado.

Por outro lado, ninguém ignora que a Física atual exige organizações ciclópicas, dobrando as fôrças políticas às suas imposições avassaladoras: de certa forma, é a Técnica que tende a modelar o Estado à sua imagem.

Como já ponderava o nosso Ruy Barbosa, podem os cientistas descobrir no infinitamente pequeno um mundo novo, não menos estranho e poderoso do que o infinitamente grande; assim como estrair da fisiologia das células vivas a teoria da velhice e da morte, mas tôdas essas conquistas da ciência não bastarão para satisfazer a consciência humana: "Adoecer um pouco menos, viver um pouco mais, será êsse o desideratum, que absorve as preocupacões eternas de nossa espécie"?

Se da ciência não podemos esperar a eliminação de nossas inquietações mais profundas (nem é essa tarefa que the pertença), devemos ao menos cooperar para que ela não seja mero instrumento nas mãos dos que possam gerar ou agravar as angústias da espécie humana.

Um ideal pode ser concebido pelo filósofo, neste passo. e é o da ciência autônoma, pela autonomia dos homens da ciência. 
Se, com efeito, há algo de urgente e de imediato a fazer, por mais que pareça utópico, não é, por certo, pretender estancar a fonte inspiradora e revolucionária das ciências, mas antes pugnar para que elas se emancipem e deixem de estar a serviço dêste ou daquele grupo em conflito. Só assim, corresponderemos à plena responsabilidade que cabe aos homens de pensamento no mundo atual: a preservação da paz, que se identifica com as exigências mesmas da liberdade instituidora do espírito. 